\title{
The Key Determinant Factors for Social Sustainability in Traditional Settlement
}

\author{
Najiha Jaffar ${ }^{1}$, Nor Zalina Harun ${ }^{1}$, Mazlina Mansor ${ }^{2}$ \\ ${ }^{1}$ Institute of The Malay World and Civilization, \\ The National University of Malaysia, 43600 Bangi, Selangor, Malaysia \\ 2 Department of Landscape Architecture, Kuliyyah of Architecture and Environmental Design, \\ International Islamic University Malaysia, Gombak, 53100, Selangor, Malaysia \\ najihajaffar13@gmail.com, nzalina@ukm.edu.my,mmazlina@iium.edu.my \\ Tel: +60192490357
}

\begin{abstract}
Successful traditional settlements refer to a settlement environment that spontaneously built by residents who consider their existing site integrates with excellent social sustainability indicators. This study aims to determine the critical factors of physical character for social sustainability of a traditional settlement with the objective to identify the types of physical characteristics deemed as significant in daily social interaction among the locals. To achieve this, a quantitative method was employed using questionnaire survey distributed to 400 residents in two historic settlements, namely Kampung Pulau Duyong and Kampung Losong located at Kuala Terengganu. Both sites are selected due to good conservation practices observed concerning the physical landscape. The results generated from the Exploratory Factor Analysis (EFA) revealed eleven factors (11) related to social sustainability. Such factors then categorised into six latent factors, which are the preservation of local identity, safety, provision of infrastructure, natural qualities, accessibility, and availability of public spaces. The findings recall the relationship between physical aspects and social sustainability as a step towards improvement in historic site preservation efforts.
\end{abstract}

Keywords: social sustainability; traditional settlement; factor analysis; Kuala Terengganu

eISSN: 2398-4287 @ 2019. The Authors. Published for AMER ABRA cE-Bs by e-International Publishing House, Ltd., UK. This is an open access article under the CC BYNC-ND license (http://creativecommons.org/licenses/by-nc-nd/4.0/). Peer-review under responsibility of AMER (Association of Malaysian Environment-Behaviour Researchers), ABRA (Association of Behavioural Researchers on Asians) and cE-Bs (Centre for Environment-Behaviour Studies), Faculty of Architecture, Planning \& Surveying, Universiti Teknologi MARA, Malaysia. DOI: https://doi.org/10.21834/e-bpj.v4i12.1944

\subsection{Introduction}

The concept of sustainability emerged in the 1960s in response to the doubts about environmental degradation due to poor resource management. It is the result of severe weakness in the ecological balance, economic stability and security of natural resources occurred in the industrialised countries from the 1960s to the 1970s (Michael \& Peacock, 2011; Hajirasouli \& Kumarasuriyar, 2016). Since then, various definitions have been formulated with the concept of sustainability has consistently considered in a balanced, economic and social environment in planning development and improving the quality of life. This study aims to determine the critical factors of physical character for social sustainability of a traditional settlement to identify the types of physical characteristics deemed as significant in daily social interaction among the locals.

eISSN: 2398-4287 (C) 2019. The Authors. Published for AMER ABRA cE-Bs by e-International Publishing House, Ltd., UK. This is an open access article under the CC BYNC-ND license (http://creativecommons.org/licenses/by-nc-nd/4.0/). Peer-review under responsibility of AMER (Association of Malaysian Environment-Behaviour Researchers), ABRA (Association of Behavioural Researchers on Asians) and cE-Bs (Centre for Environment-Behaviour Studies), Faculty of Architecture, Planning \& Surveying, Universiti Teknologi MARA, Malaysia. DOI: https://doi.org/10.21834/e-bpj.v4i12.1944 


\subsection{Literature Review}

Previous researches have provided a clear explanation that social sustainability happens when formal and casual procedures, frameworks, structures and connections effectively bolster the limit of future generations. The concept aims to create opportunities, making decisions, convenience and healthy communities, hence lead to a high quality of life. These can only be accomplished through effective use of natural resources, safeguard the environment, promote social cohesion and strengthen economic prosperity. Alongside the primary indicators of social sustainability mentioned, Barron and Gauntlett, (2002) discover that physical properties are of significance in the urban area. According to the scholars, the physical properties are what make society trustworthy and decent. Having a good quality and effective provision of physical properties have assisted the community in raising their equity, variety, interconnectedness, quality of life, democracy and good governance (Bramley et al., 2006). In the same breadth, Colantonio (2008), demonstrates how essential needs and value works as principal mainstays of social sustainability. The subsequent investigation of social sustainability topics also illustrates how these customary subjects, for example, equity, poverty reduction and livelihood, are progressively harmonised by more intangible such as identity, sense of place and the advantages of social networks. Furthermore, Chan and Lee (2008) acknowledged how physical properties belong to a community lead to 6 good social sustainability indicators. The indicators include 1) facilitate daily life operations 2) satisfaction of welfare requirements 3) creation of harmonious living environment 4) conservation of resources and the surroundings 5) good form of development and 6) availability of open spaces.

The frameworks of social sustainability generally start from a constructivist or transactional perspective, wherein the conservation of social culture is seen as the underlying component in determining sustainable community and people wellbeing (Davidson, 2009). On the other hand, Pitarch-Garrido (2018) elaborated that the framework for the creation of socially sustainable communities requires a good combination between physical design with people's need. For example, providing infrastructure to support social and cultural life, providing systems that engage communities, providing space for people and space to evolve (Woodcraft, Hackett \& Caistor-Arendar, 2011). Recently works by Primoz (2017) and Hajirasouli and Kumarasuriyar (2016) lend support to extend the components resided in the social sustainability concept in which he refers social development in society, the character of the landscape and social spaces as the essential elements to ensure the quality of social and community development. Overall, social sustainability as a process of building a harmonious society by meeting the basic needs of the community and taking into account the principles of social justice, equity, diversity, sense of place, social convenience, and social security.

The progress of social sustainability concept is explained not only by the list of indicators involved but also by the design and development of two leading examples of sustainable economic that used different implementation strategies. The strategies are the topdown development and bottom-up (participatory) approach in Vauban (Primoz, 2017). The result shows that the principle of new urbanism is closely related to walkability, connectivity, mixed-use and diversity, mixed housing, quality architecture, traditional neighbourhood structure, density and transportation. Considering this, Eizenberg and Jabareen (2017) propose a comprehensive conceptual framework of social sustainability composed of four interrelated concepts of socially oriented practices. Each idea has a distinctive function in the context and incorporates significant social aspects, namely 1) equity 2) safety 3) eco-presumption and 3) good urban form. Besides, other factors contributed to the quality of life are including demographic factors such as level of education, the length of residence, household size, and ages (Okunola, Adebayo \& Amole, 2018); quality of housing (Ali et al., 2018) and residents' social interaction (Wang, Pan \& Hadjri, 2018; Ibrahim, Omar \& Mohamad, 2019).

Lastly, the study is synopsised by Pitarch-Garrido (2018) which concentrated on the accessibility of public services using GISs, and spatial equity authorises the ability to access public services is one of a simple way of quantifying social sustainability. The study presents how the exchange on social sustainability is an intricate subject demonstrating human rights, labour rights, and the administration. Table 1 summarises the significant underlying factors emphasised in global literature attributed to social sustainability.

Table. 1. Summary of social sustainability concentrations

\begin{tabular}{|c|c|c|}
\hline Researcher & \multicolumn{2}{|c|}{ Social sustainability concentrations } \\
\hline $\begin{array}{l}\text { Barron \& Gaunlett, 2002; } \\
\text { Hajirasouli \& Kumarasuriyar, } \\
2016\end{array}$ & $\begin{array}{ll}\checkmark & \text { Equitable opportunities and outcomes } \\
\checkmark & \text { Promotion and encouragement of diversity and value of } \\
\text { the difference }\end{array}$ & $\begin{array}{ll}\checkmark & \text { Quality of life } \\
\checkmark & \text { Democracy and governance }\end{array}$ \\
\hline $\begin{array}{l}\text { Bramley et.al, 2006; } \\
\text { Hajirasouli \& Kumarasuriyar, } \\
2016\end{array}$ & $\begin{array}{ll}\checkmark & \text { Interactions in the community } \\
\checkmark & \text { Community participation } \\
\checkmark & \text { Pride and sense of place }\end{array}$ & $\begin{array}{ll}\checkmark & \text { Community stability } \\
\checkmark & \text { Security }\end{array}$ \\
\hline $\begin{array}{l}\text { Colantonio, 2008; Davidsson, } \\
\text { 2009, Michael \& Peacock, } \\
\text { 2011; Wang \& Hadjiri, } 2018\end{array}$ & $\begin{array}{ll}\checkmark & \text { Identity, sense of place and culture } \\
\checkmark & \text { Empowerment, participation, access } \\
\checkmark & \text { Health and safety } \\
\checkmark & \text { Well-being, happiness, quality of life }\end{array}$ & $\begin{array}{ll}\checkmark & \text { Social capital } \\
\checkmark & \text { Demographic change } \\
\checkmark & \text { Social mixing and cohesion }\end{array}$ \\
\hline Chan \& Lee, 2008; & $\begin{array}{ll}\checkmark & \text { The satisfaction of welfare requirements } \\
\checkmark & \text { Conservation of resources and the surrounding } \\
\checkmark & \text { Creation of a harmonious living environment }\end{array}$ & $\begin{array}{ll}\checkmark & \text { Provision facilitating daily life operations } \\
\checkmark & \text { Form of development } \\
\checkmark & \text { Availability of open spaces }\end{array}$ \\
\hline $\begin{array}{l}\text { Woodcraft et.al, 2011; Primož, } \\
\text { 2017; Okunola et.al, 2018; }\end{array}$ & $\begin{array}{ll}\checkmark & \text { Walkability } \\
\checkmark & \text { Connectivity } \\
\checkmark & \text { Mixed-use and diversity } \\
\checkmark & \text { Mixed housing } \\
\checkmark & \text { Quality architecture and urban design }\end{array}$ & $\begin{array}{ll}\checkmark & \text { Traditional neighbourhood structure } \\
\checkmark & \text { Increased density } \\
\checkmark & \text { Green transportation } \\
\checkmark & \text { Sustainability } \\
\checkmark & \text { Quality of life }\end{array}$ \\
\hline
\end{tabular}




\begin{tabular}{|c|c|c|}
\hline Eizenberg \& Jabareen, 2017; & $\begin{array}{ll}\checkmark & \text { Safety } \\
\checkmark & \text { Equity }\end{array}$ & $\begin{array}{ll}\checkmark & \text { Eco-prosumption } \\
\checkmark & \text { Sustainable urban form }\end{array}$ \\
\hline Pitarch-Garrido, 2018; & $\begin{array}{ll}\checkmark & \text { Accessibility } \\
\checkmark & \text { Spatial equity }\end{array}$ & \\
\hline
\end{tabular}

\subsection{Methodology}

\subsection{Study area}

Two case studies were chosen to elaborate on the factors of social sustainability of a traditional settlement. Indeed, an analysis based on only two case studies will not make a "universal" statement, but it can still open up new perspectives for further analysis and discussion. For this purpose, two settlements, Kampung Pulau Duyong (KPD) and Kampung Losong (KL) have been selected as the study area. The sites are located in Kuala Terengganu, the East Coast of the Malay Peninsula. The two settlements have several identicalness in terms of history, planning, development and socio-culture structures with different types of physical characteristic exemplify a different set of roles and values.

\subsubsection{Kampung Pulau Duyong}

Kampung Pulau Duyong Island is best known for seafarer's village developed in the late $16^{\text {th }}$ century. The village is separated from the mainland by the Terengganu River with a distance of 870 meters and the closest distance to the region is 495 meters. The settlement is made up of more than 10 villages, namely Crab Island, Ayer Club Village, Duyong School Village, Wan Su Village and Little Duyong Island Village. Before 1985, Duyong Island originally consisted of only the Great Duyong Island and the Little Duyong Island separated from each other by shallow river flows. However, due to land development and the construction of the Sultan Mahmud Bridge completed in 1990, the islands have been consolidated into one large island. The terrain shape of Duyong Island Village as a whole is a flat surface. To the east is Goat Island. Duyong Island has strategic access that can connect either by land or by waterway. The island is about 2.7 square kilometres and has 686 houses. The locals maintain the Malay culture and way of life, with over $40 \%$ of the population working as fishermen.

\subsubsection{Kampung Losong}

Kampung Losong is located near the Kuala Terengganu river with 11 sub-villages located opposite Wan Man Island. Historically, the villagers of Losong are well-known for their knowledge of the marine sciences conveyed by the Bugis community. At the same time, the local people of Kuala Terengganu are skilled in carpentry. As a result, they combine these skills to produce high-quality boats. Significant roles played by boat making activities in the early 18th and late 19th centuries have turned Kuala Terengganu into international trading port. The socio-economic activities of the villagers of Kampung Losong were songket textile businesses, small-scale trades and fishing. Nowadays, the village is growing exponentially, with more people working in the city and doing small business.

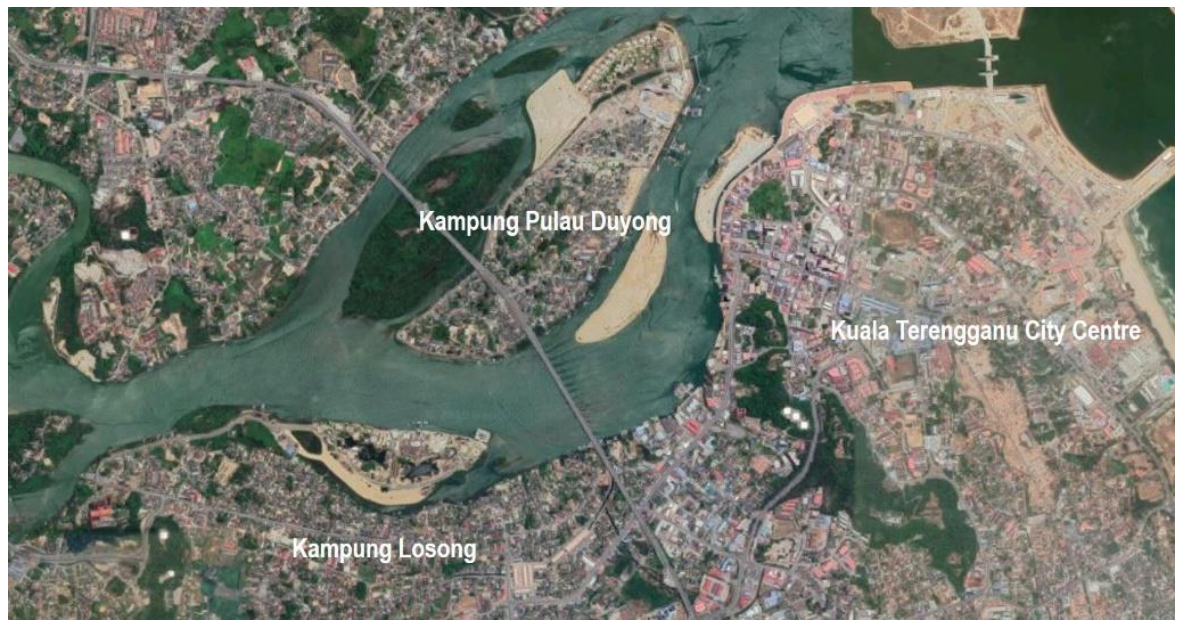

Fig. 1. Map of the study area

(Source: Google Maps, 2019)

\subsection{Data collection}

This research obtained local residents' preferences on the physical character in their settlement that influence social sustainability. The quantitative approach involved a series of survey forms distributed to over 400 respondents comprising local residents. Respondents were asked to assess the physical attributes criteria affecting social sustainability on a 5-point Likert scale ("1" = strongly disagree and "5" = strongly agree). Cluster sampling was applied for this study. Cluster sampling is a method for data collection for a sampling method where the participants of the population selected at random (Surbhi, 2016). All the respondents chosen from randomly selected clusters. 
For this study, the sample used was local residents who lived in KPD and KL that involved more than 800 local residents' houses in total, where the majority are Malays.

\subsection{Data Analysis}

The data gained from the questionnaire survey were analysed using descriptive analysis used in the Social Science Statistics Package version 25 (SPSS). Before analysis, data cleaning was done first to determine the possibility of error in entering the data into the SPSS program. Incorrect data entry may affect the results of the analysis (Julie Pallant, 2013). Once the data has cleared, the analysis process is complete. In brief, descriptive statistics are used to describe data in the form of numerical calculations, charts and tables. Factor analysis and reliability analysis were adopted in this study to analyse the data. Factor analysis was used to identify the underlying factors affecting the social sustainability of physical attributes.

\subsubsection{Exploratory Factor Analysis}

Exploratory Factor Analysis (EFA) factor Analysis with Principal Component Analysis (PCA) used in this study, which is one of the multivariate statistical correlation analyses that can be used to examine the validity of variable items. This EFA technique is used to determine the number of variables underlying a general variable. Typically, EFA analysis based on a correlation matrix between variables. Therefore, the measurement of the variables should be at least at minimum level intervals. Besides, consideration of sample size and normality distribution are also a prerequisite for using this analysis (Tabachnick \& Fidell, 2007; Yong \& Pearch, 2013).

\subsection{Findings}

\subsection{Residents profile}

The figures below report the result from the questionnaire survey conducted in KPD and KL. A total of 400 respondents have participated in the survey. Most KPD respondents $(\mathrm{N}=200)$ were male $(61.5 \%)$, while $\mathrm{KL}$ residents were female $(51 \%)$. Majority of the respondent's age is between 17-70 years old with almost fair distribution among gender. The result indicated that both settlements had a greater number of respondents among adult youth within 26 - 45 years old category. A large proportion of respondents work in private sector (KPD, 37\% and $\mathrm{KL}, 32.5 \%$ ) and self-employed (KPD, 35.5\% and $\mathrm{KL}, 25.5 \%$ ), as seen from both respondents' in the survey groups. Less than $20 \%$ remaining were students, housewife, retiree and unemployed. The majority of respondents are from the middle-income group, which earns RM1000-RM2000 a month. However, there is a significant difference in the percentage of the income of RM20013001 , which are the KL population, is more than the KPD. Beyond $65 \%$ of respondents have been residing in both villages for 11 years and above.

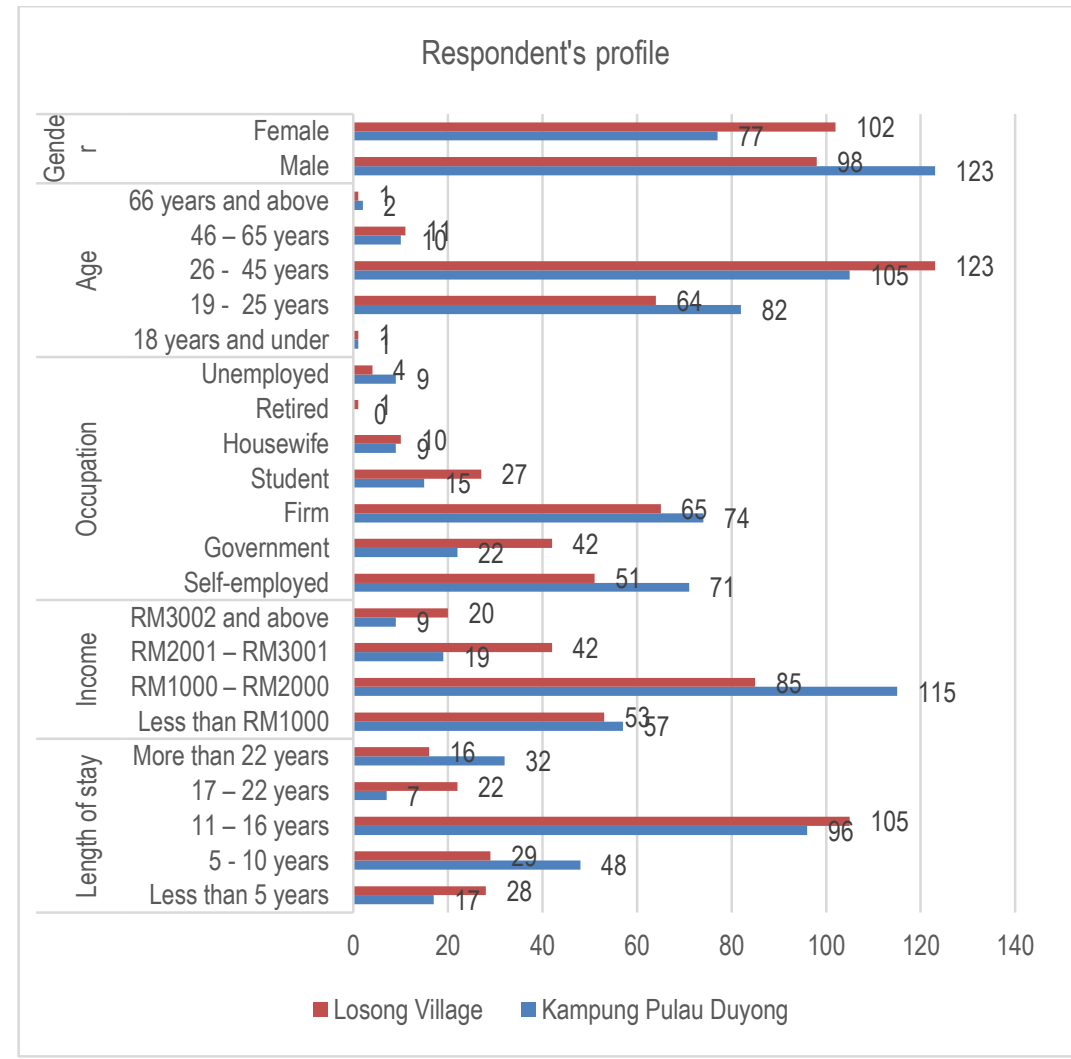

Fig. 2: Respondent's profile

(Source: Authors, 2019) 


\subsection{Sampling adequacy}

Factor analysis assessed using Principal Component Analysis (PCA) through the Statistical Package for Social Sciences (SPSS) software version 25. A number of statistical considerations have fulfilled to ensure data validity for Exploratory Factor Analysis (EFA). Through the assessment of internal consistency reliability, Cronbach's alpha values for accessibility, security, local identity, environmental quality and infrastructure facilities rated as $0.60,0.60,0.64,0.60$ and 0.55 respectively. All of these values are 0.3 and above, which stated as to have satisfactory consistency (Taber, 2018).

The collected data then tested using rotation factors. This step aims to extract the variables and categorise them. The results are as presented in Table 1. Results of the PCA analysis using varimax rotation, load value of .50 and eigenvalues $>1$ produced 11 factors. A total of 39 items have retained. All values obtained exceed 0.3. Therefore, the items found in all three constructs are accepted, and no need to be dropped (Hair et al., 2013). The factor loadings for the social sustainability components are between $.306-.829$.

Meanwhile, the obtained KMO value is 0.814 , which is higher than 0.500 . Moreover, the $\mathrm{p}$-value of the Bartlett Test is closer to 0.000 , which is less than 0.050 . It is indicate that there are correlations between variables that can be explained by other variables and the data obtained are suitable for using factor analysis (Hair et al., 2013). All eleven factors account for $63.90 \%$ of the variance in the entire set of social sustainability components. The item's social value for all of the factors formed ranged from .474 to .755 .

\subsection{Determinant factors for social sustainability}

The result showed there were 39 items related to physical attributes preferences as social sustainability indicator based on six criteria of social sustainability. In this paper, only items with factor loading at least 0.3 and above were considered as significant from the factor matrix result. Table 1 demonstrates the factor analysis summary results computed.

Table. 2. Summary of social sustainability concentrations

\begin{tabular}{|c|c|c|c|}
\hline Social sustainability indicator & Factor loading & $\begin{array}{l}\% \text { of variance } \\
\text { explained }\end{array}$ & $\begin{array}{l}\text { Cumulative } \% \text { of } \\
\text { the variance }\end{array}$ \\
\hline Preservation of local identity & & 18.828 & 18.828 \\
\hline ID5 Beaches and rivers & 0.801 & & \\
\hline ID3 Socio-economic activities & 0.753 & & \\
\hline ID2 Cultural and communal activities & 0.716 & & \\
\hline ID4 Local landmarks & 0.693 & & \\
\hline ID1 Traditional architecture & 0.629 & & \\
\hline ID6 Organic street pattern & 0.532 & & \\
\hline KS10 Well-connected road & 0.436 & & \\
\hline PS5 Peaceful beach environment & 0.306 & & \\
\hline PS5 Jetty as a business place & 0.325 & & \\
\hline Pedestrian safety & & 9.921 & 28.749 \\
\hline KS2 Clear and safe alley & 0.744 & & \\
\hline KS1 Provision of lighting street & 0.701 & & \\
\hline KS8 Vehicles driven by speed limits & 0.642 & & \\
\hline PS4 Peaceful rivers environment & 0.518 & & \\
\hline KS9 Provide separate vehicle and pedestrian route & 0.437 & & \\
\hline Neighbourhood safety & & 6.253 & 35.001 \\
\hline KS5 Abandoned house affect health and safety & 0.714 & & \\
\hline KS12 Provision of lighting street & 0.655 & & \\
\hline KS7 Clear and widen the road & 0.646 & & \\
\hline KC6 Easy to access public services & 0.579 & & \\
\hline Social infrastructure & & 5.278 & 40.279 \\
\hline KM4 Satisfaction on maintenance works & 0.750 & & \\
\hline KM5 Maintenance works on time & 0.701 & & \\
\hline KM3 Strategic market location & 0.503 & & \\
\hline KS11 Accessible pedestrian route & 0.428 & & \\
\hline KM7 Strategic mosque location & 0.348 & & \\
\hline Natural qualities & & 4.328 & 44.607 \\
\hline PS1 The environment with shady trees & 0.829 & & \\
\hline PS2 The environment with shrubs and flowers & 0.806 & & \\
\hline PS3 The environment with green scenery & 0.473 & & \\
\hline Accessibility & & 3.858 & 48.465 \\
\hline KC8 Variety of communal activities & 0.691 & & \\
\hline KC5 Signage provided to convey information and street direction & 0.661 & & \\
\hline KC7 Availability of various alternatives road & 0.645 & & \\
\hline Security against crime & & 3.640 & 52.105 \\
\hline KS3 Houses built near to one another & 0.768 & & \\
\hline KS4 Fences provide safety & 0.744 & & \\
\hline Legibility & & 3.384 & 55.489 \\
\hline KC4 Mixed-used of land and spaces & 0.795 & & \\
\hline KC3 Strategic main entrance & 0.606 & & \\
\hline
\end{tabular}




\begin{tabular}{|c|c|c|c|}
\hline KC2 Proximity to business activities & 0.594 & & \\
\hline Permeability & & 2.923 & 58.412 \\
\hline KC1 Well-connected road & 0.804 & & \\
\hline KS6 Availability of crossing facilities & 0.676 & & \\
\hline Communal spaces & & 2.910 & 61.322 \\
\hline KM2 Padang as gathering spaces & 0.747 & & \\
\hline KM6 Community hall supporting the communal activities & 0.614 & & \\
\hline Recreational spaces & & 2.579 & 63.901 \\
\hline KM1 Padang as recreational spaces & 0.806 & & \\
\hline
\end{tabular}

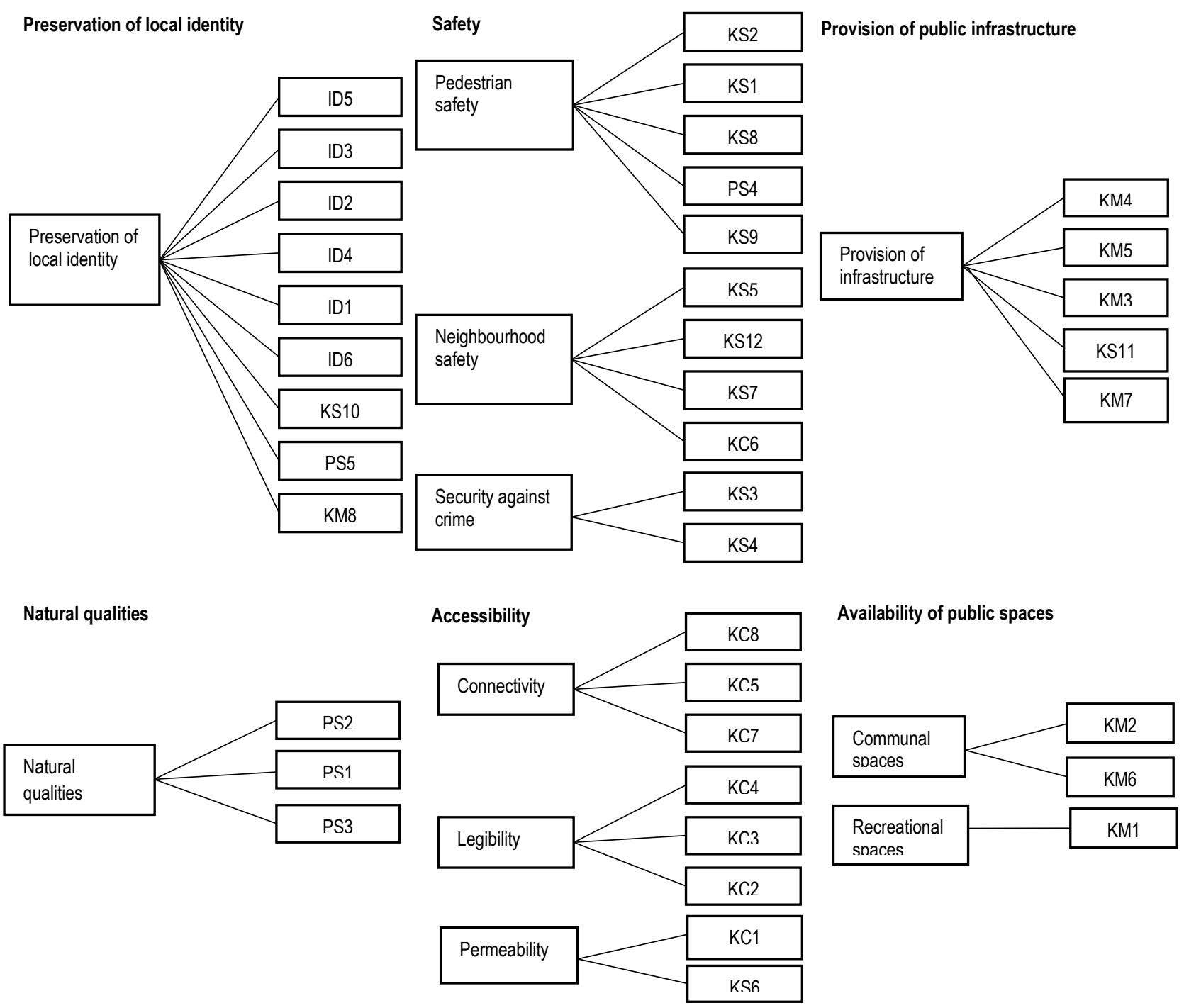

Fig. 3: Extracted factors of social sustainability criteria (Source: Authors, 2019)

Furthermore, based on Table 1, social sustainability factors explain the extracted factors. Initially, social sustainability criteria have divided into five components that have labelled using their respective codes: accessibility (KC), safety (KS), local identity (ID), natural quality (PS) and infrastructure (KM) consisting of 39 items. After extraction using Principal Component Analysis (PCA), all factors were classified into 11 new latent factors and then categorised into six subthemes. The suggested names for the subtheme are 1) Preservation of local identity, 2) Safety and security; consist of pedestrian safety, neighbourhood safety and safety against crime, 3) Natural quality, 4) Provision of infrastructure, 5) Accessibility; comprising of accessibility, legibility and permeability and 6) Availability of public spaces consisting of social and recreational areas (Figure 2). Overall, the most significant factor is the preservation of local identity as the most 
preferred parameter indicated by the local community. It is indicated that the residents of both settlements displaying a strong feeling of belonging to their settlement.

\subsection{Discussion}

\subsection{Determinant factors for social sustainability}

5.1.1 Factor 1: Preservation of local identity

The locals ranked coastal area and river as the highest significant criteria of the local identity. Historically, the river gave rise to one of the most famous trading ports in the east coast of Malay Peninsular all at once make the Terengganu River and the South China Sea are essential elements of the cultural landscape in Kuala Terengganu. Besides, the community relies upon the rivers and the sea for their source of revenue as a fisherman.

Secondly, the economic activities take place mainly at Kuala Terengganu markets such as Pasar Besar Kedai Payang and shophouses. Small-scale industries are expanding in producing the local goods that contribute to the culture of the Malay community. The market and shophouses were leading as an exchange place for domestic product coming from the local handicraft industry such as printed cloth, woven fabric, carved products and traditional food. Among the villages that supplied their products to this market are including KPD and KL. Thirdly, the locals of KPD and KL were conservative socially and deeply Islamic in religion. Culture and religionbased comprise the more significant piece of their usual activities. The presence of public venues, for example, mosques, surau, shops, and open spaces have supported the act of interactive exercises and fostered the spirit of helping each other in holding feasts. It has actuated a closer relationship among the residents. Following the passage of time, surprisingly, a group of people who appreciate the cultural heritage is growing, especially at KPD. They perform several activities related to Terengganu identities such as poetry recital, classic exhibition, postcard delivery and many more. Besides, these activities also held at the most prominent local landmarks of Kuala Terengganu such as Kota Lama Duyong at KPD and Rumah Haji Wan Su at KL. At the same time, it will promote the Malay culture and identity of Terengganu towards visitors and increase the awareness of a sense of belonging among the locals. Furthermore, the result supports the previous study that indicated the heritage should preserve for the good of future generations (Chan \& Lee, 2008; Ginting \& Rahman, 2016).

\subsubsection{Factor 2: Safety}

All the assessment items in the safety settings of the survey agreed with worth value 0.4 and above. The separated route can reduce the number of conflicts between pedestrians and vehicles on the street. A reduction in pedestrian-vehicle disputes resulted in a decreased amount of traffic collisions. Pedestrians can move freely within the neighbourhood street without worrying about the possible danger. Crosswalk signs suggest being available on the main road. In spite of this, all the security items on pedestrians' safety are wellevaluated, including the traffic safety items.

On the other hands, nowadays, almost $40 \%$ of houses at both residential neighbourhood KPD and KL using fences to protect their home. This concept does not create divisions within communities despite the physical barriers between and within neighbourhoods that alter street connectivity and permeability. This physical separation does not give negative social impacts on interaction with their neighbours and non-residents. Through this concept, fences used as safety measures to reduce and control access, increase surveillance subsequently and reduces crime occurrences (Eizenberg \& Jabareen, 2017). Besides, the houses situated near to each other can serve to lower the risk of wrongdoing as the individuals can observed from the streets.

\subsubsection{Factor 3: Provision of public infrastructure}

Provisions of public infrastructure are suitable for social prosperity as they help to improve the social wellbeing, personal satisfaction of gatherings, lessen social imbalance, and enhance community pride. In term of maintenance works, there is a need for commitment from all parties, including the municipal and community for improved maintenance of services. This commitment is usually shown through local consultation and dialogue between authorities and community representatives. At that point, there is an exchange off between what the community needs and what the authorities ready to supply. This notion is supported by Bramley et al. (2006) and Primoz (2017) who agreed that proper maintenance is one of the noticeable indicators in increasing the quality of sustainable settlement. Also, in line with studies by Hajirasouli and Kumarasuriyar (2016), social sustainability can be attained when the work of community and local institutional plans meets the human need and protects natural resources.

On the other hand, accessibility of pedestrian route is fulfilled to intend in ensuring the comfortable environment through the suitability of the route location and availability of seating. The condition of the pedestrian route in KPD and KL are proximity, convenience and acceptable as in line with the literature (Chan \& Lee, 2008) with ranked as a significant indicator by their community with as much value 0.428. Meanwhile, centricity concepts at the KPD and KL show the placed mosque in the middle of the settlement. This situation is influencing the number of people who visited the mosque with a minimum travel distance of about 10 meters from their settlement area. Meanwhile, in KPD and KL, markets act as a focal point for residents and as a hub of connection and social communication. Markets drive as crucial sites of sociability where friends and families trade together and form a particular network, or where dealers and regular customers become more acquainted with one another after some time.

\subsubsection{Factor 4: Natural qualities}


A neighbourhood should not only be available and functional. It must also be power on ethical design principles to make the surroundings outwardly engaging. The natural qualities preferences consist of 3 indicators which are the environment with shady trees, shrubs and flowers and green scenery. A green panorama with lots of trees can add a lot of value and character to a neighbourhood. Canopy trees and lush landscaping offer some beautiful shade and quiet serenity all the time. Elegant well-established localities often have a thriving, dense tree canopy, trees that have been growing there for years. The shade and character offered by big trees can add more than just aesthetics. Beautiful scenery landscaped grounds and architectural details incorporated into the neighbourhood plan, so there is always something that grabs one's eye.

The individuals' view of the useful affordances of green space for their wellbeing and prosperity may control their positive responses to green scenery. Following these thoughts, the result demonstrated that KPD and KL have significant preferences for simulated natural and built environments that measurably intervene by the more prominent disposition improving the capability of natural scenes. These findings were concordant with the previous studies (Hamdan, Khalid \& Baba, 2017), which stated the good natural environment could indeed create positive mood effects on mental and physical health by enhancing happiness.

\subsubsection{Factor 5: Accessibility}

Accessibility refers to a person's ability to obtain the right and service, activities they desire or the destination they want to reach (PitarchGarrido, 2018). Accessibility has nine indicators which all of them related to connectivity, legibility and permeability. As shown in Table 1 , the results on the factor loading values of each of the indicators found in both settlements show a high positive response. The accessibility includes close travel distances, a safe road system and mixed-used of land and spaces. Connectivity provides an efficient transaction network in the neighbourhood. Based on the results, more than $50 \%$ of dwellings in both settlement with accessible walking in $500 \mathrm{~m}$ to reach multiuse activities like shops or any services institutions, religious institution and public spaces. Facilities such as a well-defined main entrance and directional signs provided also influence the living comfort of residents. The purpose of signage is to provide clear direction on location and improve street legibility for the pedestrian to get familiar with the street environment. The results show that it is essential to place the signage before the street junctions to inform the street users on any possible danger.

Based on the findings, the settlement streets need to have well-connected roads with the shortest path within the neighbourhood area. In agreement with the previous study by Pitarch-Garrido, 2018 and Ali et al., 2018, the study explained how the pedestrians have certain limitations on walking affordances; for which the quicker the time it takes to reach the destination, the more preferable and comfortable it is to the pedestrians. The findings also suggested that a high quality of neighbourhood should offer communal consistency activities to encourages active involvement among its user's as well as generates the feeling of excitement of being outdoors.

\subsubsection{Factor 6: Availability of public spaces}

Availability of public spaces has three items in which all of them related to communal and recreational areas. This factor explains the importance of the neighbourhood to provide accessible and well-designed open spaces in the community. Based on the results revealed, the function of both public spaces as a place for recreational interaction whereby crowds discovered at every intersection engaged in various activities like relaxing, jogging, playing football, selling and buying. It is mainly due to the form and strategic location of the field in which its openness and vast ground made it legible for visitors to reach. Besides, recreational facilities offered at the field and other supporting facilities such as plenty of seats and shady spaces at its surrounding area often fulfil the needs of every resident. Being located in front of the river has made KPD incomparable to the other recreational areas that typically serve one exact role with a monotonous view at times. These findings reveal the role of public space as a public land and ceremonial space, square, district, node and landmark. Based on the results, KPD and KL have referred to as places of importance with different activities and physical attributes by decent public places. Both fields suggest a combination of open space defined by panoramas and pleasant qualities to create a good neighbourhood and a variety of fun living spaces. Hence, indirectly, the good public spaces offer in strengthening the relationship among the residents as stressed by Ibrahim, Omar \& Mohamad (2019).

\subsection{Limitation of the study}

The following are the limitations related to the study: First, the study location focused on the traditional Malay settlement; other ethnic settlements were not selected. Second, the discussion is mainly in the context of physical characteristics of a settlement; non-physical characteristics were not included. Lastly, the role of behavioural response that may be the significant indicator of successful social sustainability in the traditional settlement was not studied.

\subsection{Conclusion and Recommendations}

Based on the review of social sustainability indicators, it can conclude that both settlements had achieved the desired standard for a small to medium size settlement. Nearly all indexes in the concept of social sustainability covered in both neighbourhoods. However, it is essential to point out that in both settlements; a fundamental aspect of maintaining and uplifting the standard of social capital development has to be improved. Both sites studied to provide a range of insights into the principles and process of sustainable settlement too. It is hoped that the local and central government can recognise both examples so that more demolition can be prevented and more good preservation of traditional settlement can be realized.

It is suggested that further research be carried out within the field of social sustainability, and Malay cultural landscape and its related area. Several research topics related to the study as follows: (i) study on the determinants factors for enhancing other sustainable values 
such as economy and environment, (ii) behavioural response in experiencing the life in traditional Malay settlement, (iii) non-physical characteristics of the Malay cultural landscape contributing to the social sustainability enhancement.

\section{Acknowledgements}

The authors would like to thank the Institute of the Malay World and Civilization, The National University of Malaysia. This work was accomplished in part with funding from Grant DCP-2017-008/3.

\section{References}

Ali, M. (2018). Interpreting the Meaning of Housing Quality towards Creating Better Residential Environment. Environment-Behaviour Proceedings Journal, 3(8), $141-148$.

Barron, L., \& Gauntlett, E. (2002). Stage 1 report-model of social sustainability. Housing and Sustainable Communities' Indicators Project. Perth, Murdoch University, Western Australia.

Bramley, G., Dempsey, N., Power, S., \& Brown, C. (2006, April). What is 'social sustainability', and how do our existing urban forms perform in nurturing it. In Sustainable Communities and Green Futures' Conference, Bartlett School of Planning, University College London, London.

Chan, E., \& Lee, G. K. (2008). Critical factors for improving social sustainability of urban renewal projects. Social Indicators Research, 85(2), 243-256.

Colantonio, A. (2008). Traditional and emerging prospects in social sustainability: 2008/02.

Dave, S. (2011). Neighbourhood density and social sustainability in cities of developing countries. Sustainable Development, 19(3), 189-205.

Davidson, M. (2009). Social sustainability: a potential for politics?. Local Environment, 14(7), 607-619.

Eizenberg, E., \& Jabareen, Y. (2017). Social sustainability: A new conceptual framework. Sustainability, 9(1), 68.

Ginting, N., \& Rahman, N. V. (2016). Maimoon Palace Heritage District in Medan, Indonesia: What we preserve and why we preserve?. Procedia-Social and Behavioral Sciences, 222, 332-341.

Hair, J. F., Black, W. C., Babin, B. J., \& Anderson, R. E. (2013). Multivariate data analysis: Pearson new international edition. Pearson Higher Ed.

Hajirasouli, A., \& Kumarasuriyar, A. (2016). The social dimension of sustainability: Towards some definitions and analysis. Journal of Social Science for Policy Implications, $4(2), 23-34$.

Hamdan, H., Khalid, N. S., \& Baba, N. F. (2017). People in City: The relation of urban park and the quality of life. Environment-Behaviour Proceedings Journal, 2(6), $311-$ 318.

Ibrahim, F. I., Omar, D., \& Mohamad, N. H. N. (2019). Human Interaction In Urban Open Spaces. Environment-Behaviour Proceedings Journal, 4(10), 188-193.

Michael, Y. M. A. K., \& PEACOCK, C. J. (2011). Social Sustainability: A Comparison of Case Studies in UK, USA and Australia.

Okunola, O. O., Adebayo, A. K., \& Amole, D. (2018). Sense of Community And Demographic Factors As Predictors Of Neighbourhood Satisfaction. EnvironmentBehaviour Proceedings Journal, 3(8), 149-156.

Pallant, J. (2013). SPSS survival manual. McGraw-Hill Education (UK).

Pitarch-Garrido, M. D. (2018). Social sustainability in metropolitan areas: Accessibility and equity in the case of the metropolitan area of Valencia (Spain). Sustainability, 10(2), 371.

Primož, M. (2017). Leading sustainable neighbourhoods in Europe: Exploring the key principles and processes. Urbani izziv, (28 (1)), 107-121.

Surbhi, S. (2016). Difference between probability and non-probability sampling. Retrieved from Key Differences website: http://keydifferences. com/differencs-betweenprobability-and-non-probabilitysampling. html\# KeyDifferences.

Tabachnick, B. G., Fidell, L. S., \& Ullman, J. B. (2007). Using multivariate statistics (Vol. 5). Boston, MA: Pearson.

Taber, K. S. (2018). The use of Cronbach's alpha when developing and reporting research instruments in science education. Research in Science Education, 48(6), 12731296.

Talmizi, N. M., Zainol, H., Teriman, S., \& Ali, N. E. (2017). Improving Community Behaviour Towards Sustainable Mobility for Liveable Neighbourhoods. EnvironmentBehaviour Proceedings Journal, 2(6), 45-51.

Wang, J., Pan, Y., \& Hadjii, K. (2018). Creative Housing Design: Promoting sustainable living in cohousing community in the UK. Environment-Behaviour Proceedings Journal, 3(8), 129-140.

Woodcraft, S., Hackett, T., \& Caistor-Arendar, L. (2011). Design for social sustainability: A framework for creating thriving new communities. Future Communities.

Yong, A. G., \& Pearce, S. (2013). A beginner's guide to factor analysis: Focusing on exploratory factor analysis. Tutorials in quantitative methods for psychology, 9(2), 79-94. 